\title{
Research on the Writing Ideas and Development Trends of Academic English Textbooks
}

\author{
Zhou $\mathrm{Xia}^{1}$, Ding $\mathrm{Jie}^{2, \text { a }}$, Zhao Guotao ${ }^{1}$ \\ ${ }^{1}$ School of Foreign Languages of Hubei Engineering University, Xiaogan 432000, China \\ ${ }^{2}$ College of Technology of Hubei Engineering University, Xiaogan 432000, China \\ adj18822684@163.com
}

Keywords: academic English; textbooks; EAP; writing idea;

\begin{abstract}
Based on the academic English textbooks published at home and abroad in recent years, this paper analyzes the characteristics of this kind of textbook. It is found that there are a wide variety of academic English textbooks in our country at present, the reason is that the researchers have not formed a unified writing idea. There is a deviation in the positioning of academic English textbooks. Therefore, on the basis of studying the relevant textbooks both at home and abroad, the author proposed a clear writing idea of academic English, which is making the nature of academic English subject clear, teaching students in accordance with their aptitude, educating students according to their need, the authenticity of material selection, organizing textbooks in a themed format and the development of the digital future. Looking forward to providing some reference for the compilation and use of Chinese Academic English textbooks.
\end{abstract}

\section{Introduction}

English for Academic Purposes (EAP) was widely used by the British cultural Council in the spring of 1975 and has been in existence for 42 years [1]. Because EAP teaching objects and objectives have something in common with our English courses in higher education, EAP teaching has also attracted a wide attention from our scholars in recent years. Since textbook is an important resource to help the users achieve the goal of the curriculum, the compilation of academic English textbooks is also a major task for EAP teaching[2]. The key factor in conducting academic English teaching is textbook. At present, the EAP textbooks in our country can not meet the specific needs of students in each majors. A good academic English textbook will play a role in the syllabus to help students master the knowledge they should master at the their stage. Although there are also a series of academic English textbooks published by Foreign language teaching and research press and Tsinghua University press. However, due to the different orientation and goal of each textbook, the learning outcomes of textbook users are not the same. The reason is that scholars have not formed a unified opinion on the compilation idea and development trend of academic English textbooks yet. Therefore, it is imminent to study the idea and development trend of the writing idea of academic English textbooks.

\section{Research Summary}

Foreign academic English textbook writers attach great importance to textbook research, and use relevant research and theory to ensure the quality and effectiveness of academic English textbooks. This article illustrates the idea and development trend of the academic English textbooks writing by taking the best developed country British as an example. In the UK, the three most widely used and well-respected academic English textbooks are Oxford EAP, EAP NOW, and Language Leader [1]. These EAP textbooks are mainly based on theories of demand analysis, content-based concepts, theories based on the use of language theory, the theory of holistic education and the theory of genre [3]. The above materials has the following characteristics in the theme selection and content arrangement: First, they cover a wide range. The teaching topics cover almost all fields, such as 
education, literature and art, intercultural communication, psychology, economics, science and technology [3]. Each unit is rich in content. They take into account the language ability and non-language ability of learners, including not only the language skills of listening, speaking, reading, writing and vocabulary, but also intercultural communication skills, teamwork skills and critical thinking skills[4].Second: they are realistic. The topics of each textbook include humanistic cultivation, characterization and social hot spots, all of which are closely related to people's real life [4]. At the same time, the specific content of each unit fully takes into consideration the practical needs of students in future study or work in English-speaking environment. For example, the writing part includes sentences, paragraphs, introductions of various types of articles, causalities, comparative categories, summarizing, quoting and other writing skills [1]. Third, step by step. From the perspective of theme arrangement, the themes that students are more familiar are listed before the unfamiliar themes. For example, compared with crime and energy, knowledge and motivational themes are arranged before. Education and literature are prior to economics. Communication and environment are located before art and psychology[1]. Under the same text theme, listening, speaking, reading and writing are integrated into several learning skills. Each learning skill includes different learning tasks and activities, taking into account the language, knowledge, skills and cultural background. This kind of teaching mode which integrates listening, speaking, reading and writing into the same theme helps teachers to combine purely isolated language teaching with thematic teaching. While promoting the development of students' language ability, it should be able to cultivate students' comprehensive ability of application and practicality and improve students' communicative skills. Under the guidance of certain theories and the basis of respect for the compilation of scientific laws, these textbooks always place the needs of students first, whether it is in the selection and arrangement of themes and contents, the authenticity of textbooks, or the overall design.

In recent years, some EAP related textbooks have been published in China. For example, according to the skills classification of listening, speaking, reading, and writing in English learning, Foreign Language Teaching and Research Press has published audio-visual colloquial textbooks "English for Academic Purpose: Listening and Speaking”, writing textbook “Academic English Writing", presenting textbook "Academic English Presenting" and comprehensive textbook "Academic Encounters:Reading and Writing". According to the nature of the discipline, Shanghai Foreign Language Education Press published "Practical Oral English for Business","The Language of Medicine","An English Course in Art" and so on. According to the nature of the subject, FLTRP also divides knowledge into science and engineering, humanities, social science, management, medicine, and synthesis, and published a series academic English textbooks for each discipline. But these textbooks do not indicate what kind of students they are suitable for. At the same time, many textbooks do not point out what kind of specific learning needs they can meet. It can be seen from the above-mentioned academic English-related teaching textbooks that despite the wide range of themes covered by various publishers, there are differences in the classification of EAP teaching textbooks. And the master of the learners' Academic English comprehensive application and professional content is biased.The reason may be due to the lack of a clear understanding of the nature of the EAP subject by the influence of the long term professional English teaching textbooks in China.

\section{Writing Ideas and Trends of Academic English Textbooks}

Making the Nature of Academic English Subject Clear. Academic English is not a professional English. It focuses on interdisciplinary common-core language teaching. Content is only a carrier of teaching. It does not need to be systematic or comprehensive, and it doesn't have to be a professional front result [6]. At present, some academic English textbooks published in our country either focus on the specialized knowledge of various disciplines, stressing on the training of professional vocabulary and basic English ability, or focus on the listening, speaking, reading and writing of English learning. It is not involved in the writing of EAP papers or the language skills of international communication, and there is a deviation from the teaching goals of EAP. 
Teaching Students in accordance with their Aptitude. Britain is a native English-speaking country. Therefore, the purpose of studying English for students is that they hope that after the EAP course, they will be able to communicate in English and continue to receive higher education in English as a medium of instruction and succeed in their academic career. For our students, though they have begun to receive English education from primary schools, but because of the lack of English-speaking environment, students can not express themselves in English. Therefore, it is not suitable for the students of our country to use foreign mature academic English textbooks or to learn from their theoretical experience directly. When writing EAP textbooks, we must consider the specific characteristics of students, and consider the actual differences existing in colleges and regions in our country, research the needs of relevant subjects in academic English, and develop EAP textbook that are in line with the characteristics of relevant subjects.

Educating Students according to their Needs. Jordan divides academic English into two major branches: professional academic English and general academic English. Professional academic English can be further divided into medical English, legal English, economic English, etc. [7]. General academic English includes literature inquiry, academic writing, academic discussion, academic report and so on. Therefore, the content of academic English textbooks should also include the content of general academic English and professional academic English. The author suggests that the academic English textbooks be divided into two parts. One part includes five categories of academic courses, which are listening, oral English, writing, reading and academic research. This part is suitable for all students who are still lacking in these aspects. The other part is to collect all professional terminology into books. Students can memorize professional words according to their needs. Only in this way can we meet the needs of the professional language communication and application ability of the students' Academic English learning.

The Authenticity of Material Selection. Kuzborska's study of material selection in the EAP reading textbook found that the selection of current materials was largely based on the teacher's intuition rather than the findings, and the range of available materials also influenced the teacher's decision[ 8]. The ultimate goal of professional English teaching should be to enable students to have the language ability to conduct international academic exchanges. Since EAP has a variety of forms, such as lectures, reports, visits, papers, and so on, EAP textbooks should also provide students with various genres of language and writing norms. The problem that the textbook does not set the target audience can be solved by specialized subject and meticulous means. The content of the textbook can be a hot issue in today's society, which is closely related to society, culture, economy, education, emotion and daily life. In addition to the traditional academic text resources, such as scientific papers, conference speeches, excerpts of newspapers and magazines, excerpts from monographs, etc., but also include some column articles, interviews, manuscripts, book reviews. High quality EAP textbooks must have accurate reader orientation. Research shows that when learners read real material, the prior knowledge, interest, and curiosity of their own reserves affect how well they are engaged in learning.

Organizing Textbooks in a Themed Format. The three highly acclaimed EAP textbooks in the UK have all highlighted the topic-based approach to teaching. That is, there are 10 to 12 topics in each textbook. reading, writing several learning skills are presented together in the same text theme.Each learning skill also contains different learning tasks and activities, taking into account the language, knowledge, skills, cultural background [1]. The theme unit navigation mode is adopted. The reading materials, listening materials, discussion topics and writing tasks are related to unit themes, so as to deepen students' understanding of the same topic. This kind of teaching mode which integrates listening, speaking, reading and writing into the same topic helps teachers to organize isolated language teaching with thematic teaching. While promoting the development of students' language ability, it should be able to cultivate students' comprehensive ability of application and practicality and improve students' communicative skills.

The Development of the Digital Future. Since the 21st century, the development and application of Internet technology has revolutionized the idea and mode of education.As an important part of curriculum teaching, the form and content of textbooks need not only consider the 
development of social economy, but also adapt to the change of learners' learning style in the new era. In recent years, various publishers have launched the university English digital products to meet the new changes of foreign language education in the Internet era of technology, the transformation of learners' adaptive learning and virtual learning. However, the development of electronic textbooks for EAP courses is extremely rare in the market. For example, the FLTRP launched a series of digital products in 2016 that included comprehensive English, university English, English majors, primary and secondary English. But it appears the lack of three-dimensional EAP electronic textbooks. We should develop electronic textbooks for EAP to keep up with the pace of digital future.

\section{Conclusion and Recommendation}

With more and more opportunities for college students to participate in international exchanges, EAP teaching occupies an increasingly important position in Chinese education at this stage.This requires the scholars to turn the focus to the EAP teaching and the compilation of the textbooks.Domestic academic English textbooks haven't formed a complete system for many years. The main reason is that scholars have never propose a textbook compilation idea suitable for China's national conditions. on the basis of studying the relevant textbooks both at home and abroad, the author proposed a clear writing idea of academic English, which is making the nature of academic English subject clear, teaching students in accordance with their aptitude, educating students according to their need, the authenticity of material selection, organizing textbooks in a themed format and the development of the digital future. Looking forward to provide some reference for the compilation and use of Chinese Academic English textbooks.

\section{Acknowledgements}

This work was financially supported by General project of Hubei Social Science Fund (2016149) ,the Science and Technology Research Project of Education Department of Hubei Province (B2017 501).

\section{Reference}

[1] Yang Yulan.Compiling Features and Enlightenment of English Academic English (EAP) Textbooks[J].A Vast View on Publishing, 2016(2):73-75

[2] Shu Dingfang, An Ling.The Characteristics and Development Trend of Overseas Academic English Guided Texts in Recent Years[J]. Foreign Language Teaching Theory and Practice, 2014(4):9-17

[3] Chazal, E. de \& L. Rodgers. Oxford EAP (Intermediate/B1+ )[M]. Oxford University Press, 2012.

[4] Cox, C. \& D. Hill. EAP NOW![M]. Pearson Education Australia, 2011.

[5] Liu Yanmei, Jia Yanyan. The Basic Classification of ESP Textbooks and Research on the Problems and Strategies of Compiling and Publishing [J] . Publishing Research,2014(9):71-74.

[6] Cai Jigang.Further Discussion on the Development of College English Teaching in China:General English and Academic English[J].Journal of Zhejiang University (Humanities and Social Science Edition), 2015(4):83 -93.

[7] Jordan B. English for Academic Purposes[M]. Carnbridge:Cambridge University Press, 1997:68.

[8] Kuzborska,I.Teacher' S Decision-Making Processes When Designing EAP Reading Materials in a Lithuanian University Set-ting[J]. Journal of English for Academic Purposes,2011,(10). 